\title{
Neutral All Metal Aromatic Half-Sandwich Complexes Between Alkaline Earth and Transition Metals: An Ab-initio Exploration
}

\section{Amlan Jyoti Kalita}

Cotton University

Prem Prakash Sahu

Cotton University

Ritam Raj Borah

Gauhati University

Shahnaz Sultana Rohman

Cotton University

Chayanika Kashyap

Cotton University

Sabnam Swabaka Ullah

Cotton University

Indrani Baruah

Cotton University

Lakhya Jyoti Mazumder

Cotton University

\section{Dimpul Konwar}

Gachon University

Ankur Kanti Guha ( $\sim$ ankurkantiguha@gmail.com )

Cotton University https://orcid.org/0000-0003-4370-8108

\section{Research Article}

Keywords: Half-sandwich complexes, dual aromaticity, topological analyses

Posted Date: May 24th, 2021

DOI: https://doi.org/10.21203/rs.3.rs-505446/v1

License: (1) (1) This work is licensed under a Creative Commons Attribution 4.0 International License.

Read Full License 
Version of Record: A version of this preprint was published at Structural Chemistry on July 7th, 2021. See the published version at https://doi.org/10.1007/s11224-021-01807-w. 


\section{Abstract}

Sandwich complexes find their interests among the chemists after the breakthrough discovery of ferrocene. Since then, a number of sandwich and half sandwich complexes were predicted and synthesized. Herein, we have theoretically proposed a series of half-sandwich complexes involving a neutral $\mathrm{Be}_{3}$ ring and transition metal. Quantum chemical calculations have shown that the proposed complexes are quite stable involving high bond dissociation energies. The thermodynamics of their formation is also favorable. The $\mathrm{Be}_{3}$ ring in all cases posses dual aromaticity which has been ascertained based on magnetic as well as topological feature of electron density.

\section{Introduction}

Discovery of the first sandwich complex $\left(\mathrm{C}_{5} \mathrm{H}_{5}\right){ }_{2} \mathrm{Fe}$, commonly known as "ferrocene", drew the attention of the chemistry fraternity in no time [1-3]. The detail structural analyses revealed that the complex may adopt two close energy conformations [4]. This was followed by the discovery of sandwich complexes involving benzene and other arene systems coordinated to transition metals via delocalized $\pi$-electrons [5]. Since then, the journey of this domain has been spectacular as numerous sandwich complexes were proposed and synthesized along and their bonding analyses were carried out [6-23]. As compared to that of a full sandwich complex where the metal centre is enclosed on both sides, half-sandwich metallocenes involve a metal atom or ion enclosed on one particular side only. The inception of half-sandwich complex took place almost parallel to the discovery of ferrocene when Fischer and Hafner carried out the synthesis of tetracarbonyl (cyclopentadienyl) vanadium complex, $\mathrm{C}_{5} \mathrm{H}_{5} \mathrm{~V}(\mathrm{CO})_{4}$ [24]. This was followed by the synthesis of half-sandwich compounds containing manganese and cobalt as metal centers [25-26]. Recently, Pan et. al synthesized all metal aromatic sandwich compound $\left[\mathrm{Sb}_{3} \mathrm{Au}_{3} \mathrm{Sb}_{3}\right]^{3-}$ where $\mathrm{Au}_{3}$ ring is sandwiched by two cyclo- $\mathrm{Sb}_{3}$ rings [27]. It is worth mentioning here that previously such all metal sandwich complexes have been predicted theoretically [28-35].

Although all metal sandwich complexes have so far been significantly explored, the library of such complexes involving s-block metal as ligand fragment is not adequate so far [36-37]. Through this $a b$ initio study, we have designed a series of all metal neutral half sandwich complexes (Scheme 1) involving $\mathrm{Be}_{3}$ fragment attached to transition metals. The reason of taking cyclic $\mathrm{Be}_{3}$ fragment is due to the fact that it can act like a Z-type ligand owing to the presence of vacant $\pi$ symmetric orbital. The structure and reactivity of $\mathrm{Be}_{3}$ is well established [38-40]. The proposed half sandwich complexes feature donoracceptor interaction between the transition metals and the $\mathrm{Be}_{3}$ fragment. These complexes are quite stable owing to their high bond dissociation energies and also with favorable thermodynamics.

\section{Computational Details}

All the molecules were fully optimized without any symmetry constraints in their gas phase at PBE1PBE [41], MP2 [42] and CCSD level of theory using $6-311++G^{* *}$ basis set for Be atom and SDD[43] basis set 
for transition metals. Harmonic frequency calculations were performed at the same level of theory to characterize the nature of stationary states. The global minima structures have all real values of frequencies. All energies are zero point and thermal corrected. Natural bond orbital analyses (NBO) [44] were performed at PBE1PBE/SDD level of theory to get the precise idea of the frontier orbitals as well as electronic structure of the molecules. All calculations were performed using Gaussian 16 suite of program [45]. Quantum theory of atoms in molecules (QTAIM) [46], electron localization function (ELF) [47-48] and Charge decomposition analysis (CDA) [49] were performed at PBE1PBE level of theory using Multiwfn program code [50].

\section{Results And Discussion}

Fig 1 shows the optimized geometries of the molecules. All these molecules are closed shell singlet in their global minima with $C_{3 \mathrm{v}}$ symmetry. The relative energies of different possible isomers are listed in Table S1, supporting information. Among the studied systems, the frontier molecular orbitals of the $\mathrm{Be}_{3}$ $\mathrm{Fe}$ and $\mathrm{Be}_{3}-\mathrm{Zn}$ has been shown (Fig 2). The Be-Be distance in metal free cyclic $\mathrm{Be}_{3}$ molecule is $2.210 \AA$ which significantly shortens in the half sandwich complexes (Fig 1). The Wiberg bond indices for the TMBe bonds, a measure of bond strength, are close to 0.9 for $\mathrm{Fe}, \mathrm{Ru}$ and Os complexes while they are lower ( 0.2) for the $\mathrm{Zn}, \mathrm{Cd}$ and $\mathrm{Hg}$ complexes.

To investigate the mode of binding of $\mathrm{Be}_{3}$ fragment with the transition metals, we calculated the energy changes while displacing the transition metal atom from the centre to a distance $r$ as shown in Scheme 2. Results based on single point calculations at PBE1PBE level of theory (Fig 3) reveals that all these complexes have the lowest energy at $r=0$, i.e., $\mathrm{Be}_{3}$ fragment in these complexes feature $\eta^{3}$ coordination mode.

Further to investigate the nature of bonding, we have performed charge decomposition analysis (CDA) Fe and $\mathrm{Zn}$ complexes respectively as representative case. Fig 4 shows the interaction diagram. The LUMO (lowest unoccupied molecular orbital) and LUMO+1 of $\mathrm{Be}_{3}$ fragment interact with the metal $\mathrm{d}_{\mathrm{z}}{ }^{2}$ and $\mathrm{s}$ orbital. It is to be noted that the LUMO of $\mathrm{Be}_{3}$ fragment is a delocalized unoccupied $\pi$ symmetric oribital while the LUMO+1 is the $\sigma$ orbital. Occupation of these orbitals in the sandwich complex is expected to enhance aromaticity in the cyclic $\mathrm{Be}_{3}$ fragment.

We then turned to the aromaticity of the proposed molecules by performing nucleus independent chemical shift (NICS) calculations at the centre of the $\mathrm{Be}_{3}$ fragment in the complexes which is known as $\operatorname{NICS}(0)$ and $1 \AA$ above the plane which we designated as NICS(1) [49] (Scheme 3, Table 1). It is worth mentioning that $\mathrm{Be}_{3}$ ring is anti-aromatic which is backed by positive $\mathrm{NICS}(0)$ value of $20 \mathrm{ppm}$. Upon complexation with the considered transition metals, significant aromaticity is induced in the $\mathrm{Be}_{3}-\mathrm{TM}$ complexes. In all the complexes, aromaticity is dominated by NICS(0), a measure of $\sigma$ aromaticity. However, NICS(1) values, a measure of $\pi$ aromaticity, are also significant. Thus, the calculated values of NICS suggest that the proposed sandwich complexes have dual $\sigma$ and $\pi$ aromaticity [51]. The presence of 
dual aromaticity is expected to increase the stability of the complexes. We therefore, calculated the bond dissociation energies (BDE, Table 2) and change in Gibbs free energies $\left(\Delta G_{298}\right)$ of their formation according to the following equation

Table 1: PBE1PBE calculated NICS values (ppm) of the proposed half-sandwich complexes.

\begin{tabular}{|lll|}
\hline Complexes & NICS (0) (ppm) & NICS (1) (ppm) \\
\hline $\mathrm{Be}_{3}-\mathrm{Fe}$ & -31.57 & -4.33 \\
\hline $\mathrm{Be}_{3}-\mathrm{Ru}$ & -25.45 & -7.71 \\
\hline $\mathrm{Be}_{3}-\mathrm{Os}$ & -34.53 & -11.4 \\
\hline $\mathrm{Be}_{3}-\mathrm{Zn}$ & -38.38 & -15.72 \\
$\mathrm{Be}_{3}-\mathrm{Cd}$ & -35.48 & -14.15 \\
\hline $\mathrm{Be}_{3}-\mathrm{Hg}$ & -32.45 & -12.81 \\
\hline
\end{tabular}

Table 2: Bond dissociation energies (BDE, $\mathrm{kcal} / \mathrm{mol}), \Delta \mathrm{G}_{298}(\mathrm{kcal} / \mathrm{mol})$ of formation of proposed sandwich complexes and force constant, $k$ (mDyne/Å).

\begin{tabular}{|llll|}
\hline Complex & BDE & $\Delta \mathbf{G}_{298}$ & $\mathbf{k}$ \\
\hline $\mathrm{Be}_{3}-\mathrm{Fe}$ & 96.17 & -88.14 & 1.278 \\
$\mathrm{Be}{ }_{3}-\mathrm{Ru}$ & 154.86 & -146.71 & 1.546 \\
$\mathrm{Be}_{3}-\mathrm{Os}$ & 187.83 & -179.65 & 1.323 \\
$\mathrm{Be}_{3}-\mathrm{Zn}$ & 37.33 & -29.67 & 0.62 \\
$\mathrm{Be}_{3}-\mathrm{Cd}$ & 32.56 & -25.05 & 0.43 \\
$\mathrm{Be}_{3}-\mathrm{Hg}$ & 24.70 & -17.25 & 0.32 \\
\hline
\end{tabular}

The BDE values were calculated by considering the neutral $\mathrm{Be}_{3}$ and transition metal fragment. It is evident from Table 2 that all these complexes have high bond strength. The calculated BDE values are higher for Fe, Ru and Os while they are lower for $\mathrm{Zn}, \mathrm{Cd}$ and $\mathrm{Hg}$. The calculated values of the force constant ( $k$, Table 2) are also higher for Fe, Ru and Os. Moreover, the change in Gibbs free energies $\left(\Delta G_{298}\right)$ for their formation is more negative for $F e, R u$ and $O$ s. However, $\Delta G_{298}$ values are negative in all cases suggesting their favorable thermodynamics of formation.

We then further analyzed the topological feature of electron density within the realm of quantum theory of atoms in molecules (QTAIM) [46] and electron localization function (ELF) [47-48]. QTAIM is based on 
topological properties of electron density and its derivatives. It describes the concept of bonding with the help of bond paths and critical points. The electron density $(q)$ exhibits a maximum, a minimum, or a saddle point in space. These points are referred to as Critical Points (CPs). At this point, the first derivatives of $\mathrm{q}(\mathrm{rc})$ vanishes. The Laplacian $\left(\nabla^{2} \rho\right)$ plays a very vital role in the characterization of chemical bonding. Generally, for covalent interactions (also referred to as "open-shell" or "sharing" interactions), the electron density at the bond critical point (BCP), pb, is large ( $>0.2 \mathrm{a} . \mathrm{u})$ while its laplacian, $\nabla^{2} \rho$ is large and negative. On the other hand, for closed-shell interactions (e.g., ionic, van der Waals, or hydrogen bonds), $\rho b$ is small ( $<0.10 \mathrm{au}$ ) and $\nabla^{2} \rho$ is positive. However, a clear distinction between the closed-shell and covalent type of interaction is impossible without determination of the local electronic energy density, $H(r)$. The local electronic energy density, $H(r)$, given by $H(r)=G(r)+V(r)$, where $G(r)$ and $V(r)$ are the local kinetic and potential energy densities, is negative for an interaction with significant covalent character and accounts for the lowering of potential energy of electrons at BCPs. The magnitude of $\mathrm{H}(\mathrm{r})$ reflects the "degree of covalency" present in a given interaction. Thus, some covalent (some polar bonds, donor-acceptor bonds, etc.) bonds are associated with positive values of $r 2 \mathrm{q}$ and negative values of $H(r)$ [52]. Table 3 contains the numerical data at different bond critical points. The Be-TM bonds are characterized by positive values of laplacian, $\nabla^{2} \rho$ and negative values of local electronic energy density, $\mathrm{H}(\mathrm{r})$ suggesting polar covalent character of these bonds [52]. The presence of significant amount of electron density at the Be-Be-Be ring critical points is an indication of aromaticity [46].

Table 3. Electron density, $p$, at the bond critical point (bcp) and ring critical points (rcp), laplacian of electron density, $\nabla^{2} \rho$, local electronic energy density, $H(r)$ and electron localization function, ELF values. All values are in a. $u$. 


\begin{tabular}{|llllll|}
\hline Molecule & bcp/rcp & $\boldsymbol{\rho}$ & $\boldsymbol{\nabla}^{2} \boldsymbol{\rho}$ & $\mathrm{H}(\mathbf{r})$ & ELF \\
\hline $\mathrm{Be}_{3}-\mathrm{Fe}$ & Be-Fe bcp & 0.058 & 0.077 & -0.028 & 0.22 \\
& Be-Be-Be rcp & 0.043 & 0.044 & -0.006 & 0.43 \\
\hline $\mathrm{Be}_{3}-\mathrm{Ru}$ & Be-Ru bcp & 0.073 & 0.068 & -0.035 & 0.18 \\
& Be-Be-Be rcp & 0.041 & 0.041 & -0.005 & 0.45 \\
$\mathrm{Be}_{3}-\mathrm{Os}$ & Be-Os bcp & 0.076 & 0.070 & -0.035 & 0.16 \\
& Be-Be-Be rcp & 0.038 & 0.036 & -0.007 & 0.48 \\
$\mathrm{Be}_{3}-\mathrm{Zn}$ & Be-Zn bcp & 0.067 & 0.068 & -0.032 & 0.18 \\
& Be-Be-Be rcp & 0.041 & 0.042 & -0.008 & 0.34 \\
$\mathrm{Be}_{3}-\mathrm{Cd}$ & Be-Cd bcp & 0.071 & 0.062 & -0.033 & 0.16 \\
& Be-Be-Be rcp & 0.032 & 0.040 & -0.005 & 0.28 \\
\hline $\mathrm{Be}_{3}-\mathrm{Hg}$ & Be-Hg bcp & 0.061 & 0.057 & -0.031 & 0.14 \\
& Be-Be-Be rcp & 0.034 & 0.044 & -0.005 & 0.28 \\
\hline
\end{tabular}

\section{Conclusion}

In conclusion, quantum chemical calculations were carried out to investigate the possibility of formation of $\mathrm{Be}_{3}-\mathrm{TM}\left(\mathrm{TM}=\mathrm{Fe}, \mathrm{Ru}, \mathrm{Os}, \mathrm{Zn}, \mathrm{Cd}, \mathrm{Hg}\right.$ ) half-sandwich complexes where the $\mathrm{Be}_{3}$ fragment is acting as $\mathrm{Z}$ type ligand. The stability of the proposed complexes is predicted by calculating BDE as well as the thermodynamic feasibility factor $\Delta G_{298}$. The $B D E$ values are found to be higher for $F e, R u$ and $O s$ complexes compared to the $\mathrm{Zn}, \mathrm{Cd}$ and $\mathrm{Hg}$ complexes. However, the BDE values for the latter complexes are also significant enough for their realization. The calculated $\Delta G_{298}$ values are found to be significantly negative for the all the geometries. Nucleus independent chemical shift (NICS) calculations suggest the presence of dual aromatic character in the cyclic $\mathrm{Be}_{3}$ fragment of the complexes which were substantiated by topological analyses. We feel that our ab initio study will attribute to the possible synthesis and characterization of the proposed complexes.

\section{Declarations}

\section{Funding information}

A. K. G. thanks the Science and Engineering Research Board (SERB), Government of India for providing financial assistance in the form of a project (project no. ECR/2016/001466).

\section{Supporting Information}


Lowest vibrational frequencies (Table S1) and cartesian coordinates of the molecules along with their energies in a.u.

\section{Conflict of Interest}

Authors declare no conflict of interest.

\section{Code availability}

Not applicable

\section{Author Information}

\section{Corresponding Authors}

Dimpul Konwar - Department of Material Science and Engineering, Gachon University, Bokjung-dong, Seongnam-si, 1342, Republic of Korea, email:dkonwar@gachon.ac.kr.

Ankur Kanti Guha - Advanced Computational Chemistry Centre, Department of Chemistry, Cotton University, Guwahati, Assam, India-781001, email: ankurkantiguha@gmail.com.

\section{Authors}

Amlan Jyoti Kalita - Advanced Computational Chemistry Centre, Department of Chemistry, Cotton University, Guwahati, Assam, India-781001.

Prem Prakash Sahu - Advanced Computational Chemistry Centre, Department of Chemistry, Cotton University, Guwahati, Assam, India-781001.

Ritam Raj Borah - Department of Chemistry, Gauhati University, Guwahati, Assam, India-781014.

Shahnaz Sultana Rohman - Advanced Computational Chemistry Centre, Department of Chemistry, Cotton University, Guwahati, Assam, India-781001.

Chayanika Kashyap - Advanced Computational Chemistry Centre, Department of Chemistry, Cotton University, Guwahati, Assam, India-781001.

Sabnam Swabaka Ullah - Advanced Computational Chemistry Centre, Department of Chemistry, Cotton University, Guwahati, Assam, India-781001.

Indrani Baruah - Advanced Computational Chemistry Centre, Department of Chemistry, Cotton University, Guwahati, Assam, India-781001.

Lakhya Jyoti Mazumder - Advanced Computational Chemistry Centre, Department of Chemistry, Cotton University, Guwahati, Assam, India-781001. 


\section{References}

1. Kealy TJ, Pauson PL (1951). Nature 168:1039.

2. Wilkinson G, Rosenblum M, Whiting MC, Woodward BR (1952). J Am Chem Soc 74:2125.

3. Fischer EO, Pfab W (1952). Z Naturforsch 7B:377.

4. Dunitz JD, Orgel LE, Rich A (1956). Acta Crystallographica 9:373.

5. Fischer EO, Hafner W (1955). Z Naturforsch 10b:665.

6. a) Wilkinson G, Cotton FA (1959). Progr Inorg Chem 1:1; b) Fischer EO, Fritz HP (1959) Adv Inorg Chem Radiochem 1:55.

7. Fischer EO, Seus D (1956). Chem Ber 89:1809.

8. Zeiss H, Tsutsui M (1957). J Am Chem Soc 79:3062.

9. Streitwieser Jr. A, Westerhoff UM (1968). J Am Chem Soc 90:7364.

10. Warren KD (1976). Bonding forces, Springer 45.

11. Werner H (1977). Angew Chem 16:1.

12. Siebert W (1988). Pure \& Appl Chem 60:1345.

13. Kuznetsov AE, Boldyrev Al, Li X, Wang LS (2001). J Am Chem Soc 123:8825.

14. Boldyrev Al, Kuznetsov AE (2001). Inorg Chem 41:532.

15. Li X, Zhang HF, Wang LS, Kuznetsov AE, Cannon NA, Boldyrev Al (2001) Angew Chem Int Ed 40:1847.

16. Clack DW, Warren KD (1980). Structure and Bonding, Electrons and Transitions 39:1.

17. Kang HS (2005). J Phys Chem A 109:1458.

18. Minyaev RM, Minkin VI, Gribanova TN (2004). Mendeleev Commun 14:96.

19. Urnėžius E, Brennessel W, Cramer CJ, Ellis JE, Schleyer PvR (2002). Science 295:832.

20. Murahashi T, Fujimoto M, Oka M, Hashimoto Y, Uemura T, Tatsumi Y, Nakao Y, Ikeda A, Sakaki S, Kurosawa H (2006). Science 313:1104.

21. Murahashi T, Fujimoto M, Kawabata Y, Inoue R, Ogoshi S, Kurosawa H (2007). Angew Chem Int Ed 46:5440.

22. (a) Murahashi T, Hashimoto Y, Chiyoda K, Fujimoto M, Uemura T, Inoue R, Ogoshi S, Kurosawa H (2008). J Am Chem Soc 130:8586; (b) Murahashi T, Usui K, Inoue R, Ogoshi S, Kurosawa H (2011). Chem Sci 2:117.

23. (a) Tatsumi Y, Shirato K, Murahashi T, Ogoshi S, Kurosawa H (2006). Angew Chem Int Ed 45:5799; (b) Murahashi T, Kato N, Uemura T, Kurosawa H (2007). Angew Chem Int Ed 46:3509; (c) Tatsumi Y, Murahashi T, Okada M, Ogoshi S, Kurosawa H (2008). Chem Commun 477; (d) Murahashi T, Mino Y, Chiyoda K, Ogoshi S, Kurosawa H (2008). Chem Commun 4061; (e) Murahashi T, Inoue R, Usui K, Ogoshi S (2009). J Am Chem Soc 131:9888; (f) Murahashi T, Takase K, Oka M, Ogoshi S (2011). J Am Chem Soc 133:14908. (g) Murahashi T, Shirato K, Fukushima A, Takase K, Suenobu T, Fukuzumi S, Ogoshi S, Kurosawa H (2012). Nat Chem 4:52. (h) Murahashi T, Kimura S, Takase K, Ogoshi S, 
Yamamoto K (2013). Chem Commun 49:4310. (I) Murahashi T, Takase K, Usui K, Kimura S, Fujimoto M, Uemura T, Ogoshi S, Yamamoto K (2013). Dalton Trans 42:10626; (j) Horiuchi S, Tachibana Y, Yamashita M, Yamamoto K, Masai K, Takase K, Matsutani T, Kawamata S, Kurashige Y, Yanai T, Murahashi T (2015). Nat Commun 6:6742.

24. Fischer EO, Hafner W (1954). Z Naturforsch B9:503.

25. Fischer EO, Fritz HP (1959). Adv Inorg Chem Radiochem 1:56.

26. Wilkinson G, Cotton FA (1959) Prog Inorg Chem 1:1.

27. Pan FX, Li LJ, Wang YJ, Guo JC, Zhai HJ, Xu L, Sun ZM (2015). J Am Chem Soc 34:10954.

28. Li X, Kuznetsov AE, Zhang HF, Boldyrev Al, Wang LS (2001). Science 291:859.

29. Mercero JM, Ugalde JM (2004). J Am Chem Soc 126:3380.

30. Mercero JM, Formoso E, Matxain JM, Eriksson LA, Ugalde JM (2006). Chem Eur J 12:4495.

31. Li X, Zhang HF, Wang LS, Kuznetsov AE, Cannon NA, Boldyrev Al (2001). Angew Chem Int Ed 40:1867.

32. Boldyrev Al, Wang LS (2005). Chem Rev 105:3716.

33. Li Z, Wu W, Li S (2009). J Mol Struct (THEOCHEM) 908:73.

34. Maslowsky E (2011). Coord Chem Rev 255:2746.

35. Lein M, Frunzke J, Frenking G (2003). Inorg Chem 42.2504.

36. Hatua K, Nandi PK (2013). J Phys Chem A 117:12581.

37. Zoellner RW (2016). Polyhedron 107:107.

38. Castro MES, Vazquez MS (2011). Comput Theor Chem 967:136.

39. Alkorta I, Fernandez CM, Campillo MMM, Elguero J (2018). J Phys Chem A 122:1472.

40. Kalemos A (2016). J Chem Phys 145:214302.

41. Perdew P, Burke K, Ernzerhof M (1996). Phys Rev Lett 77:3865.

42. Møller C, Plesset MS (1934). Phys Rev 46:618.

43. Dolg M, Wedig U, Stoll H, Preuss H (1987). J Chem Phys 86:866.

44. Reed AE, Weinhold F, Curtiss LA (1988). Chem Rev 88:899.

45. Frisch MJ, Trucks GW, Schlegel HB, Scuseria GE, Robb MA, Cheeseman JR, Scalmani G, Barone V, Petersson GA, Nakatsuji H, Li X, Caricato M, Marenich AV, Bloino J, Janesko BG, Gomperts R, Mennucci B, Hratchian HP, Ortiz JV, Izmaylov AF, Sonnenberg JL, Williams-Young D, Ding F, Lipparini F, Egidi F, Goings J, Peng B, Petrone A, Henderson T, Ranasinghe D, Zakrzewski VG, Gao J, Rega N, Zheng G, Liang W, Hada M, Ehara M, Toyota K, Fukuda R, Hasegawa J, Ishida M, Nakajima T, Honda Y, Kitao O, Nakai H, Vreven T, Throssell K, Montgomery Jr. JA, Peralta JE, Ogliaro F, Bearpark MJ, Heyd JJ, Brothers EN, Kudin KN, Staroverov VN, Keith TA, Kobayashi R, Normand J, Raghavachari K, Rendell AP, Burant JC, lyengar SS, Tomasi J, Cossi M, Millam JM, Klene M, Adamo C, Cammi R, Ochterski JW, Martin RL, Morokuma K, Farkas O, Foresman JB, Fox DJ (2016). Gaussian 16 (Revision A.03), Gaussian Inc 2016 Wallingford CT. 
46. Bader RWF (1990). Atoms in Molecules: A Quantum Theory, Oxford Univ. Press, Oxford.

47. Silvi B, Savin A (1994). Nature 371:683.

48. Becke AD, Edgecombe KE (1990). J Chem Phys 92:5397.

49. Dapprich S, Frenking G (1995). J Phys Chem 99:9352.

50. Tian L (2015). Multiwfn: A Multifunctional Wavefunction Analyzer (version 3.1), Available from: <http://Multiwfn.codeplex.com> (accessed May 22).

51. Schleyer PVR, Maerker C, Dransfeld A, Jiao H, Hommes NJRVE (1996). J Am Chem Soc 118:6317.

52. Chandrasekhar J, Jemmis ED, Schleyer PvR (1979). Tetrahedron Lett 20:3707.

53. Cremer D, Kraka E (1984). Angew Chem Int Ed Engl 23:627.

\section{Figures}
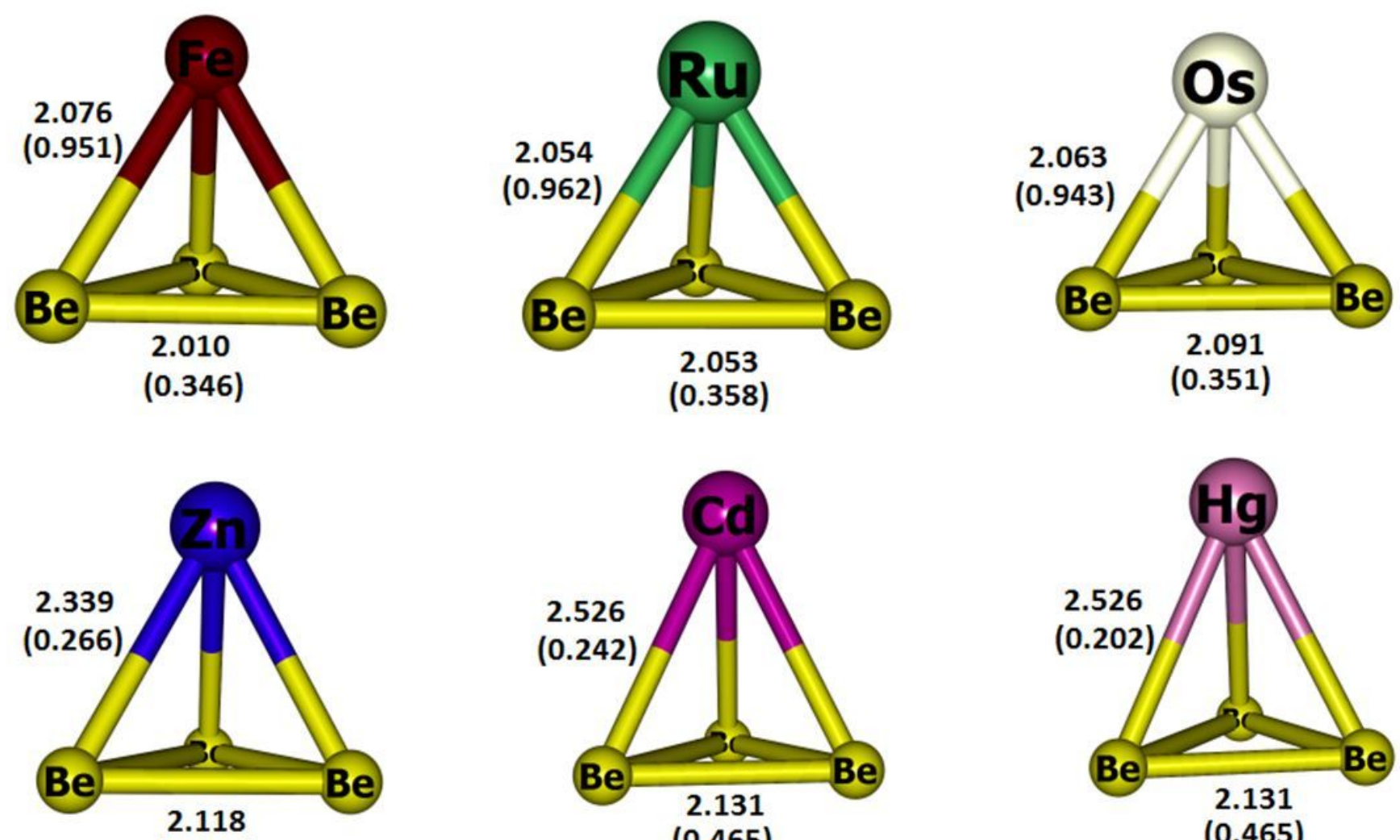

(0.471)
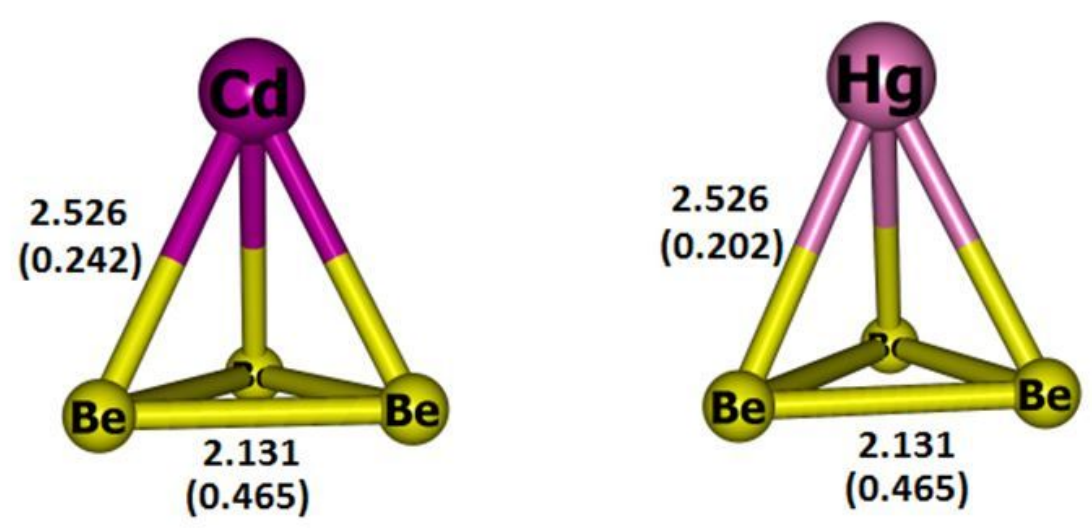

Figure 1

PBE1PBE optimized geometries of the molecules considered. Bond lengths are in $\AA$. Wiberg bond indices are given in parenthesis. 


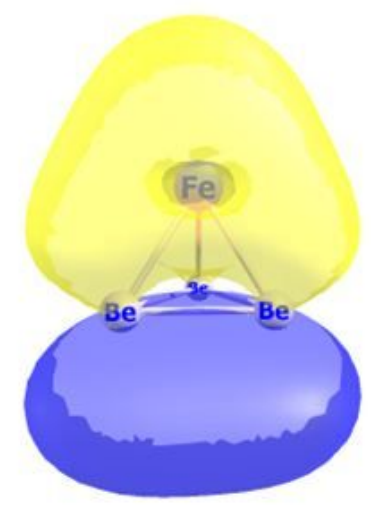

Homo

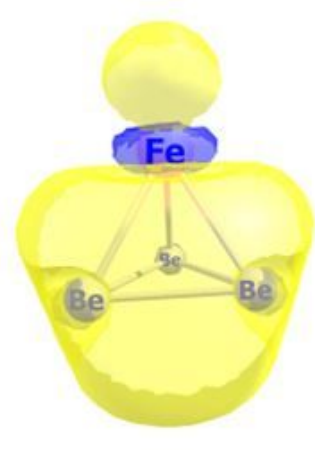

Homo-6

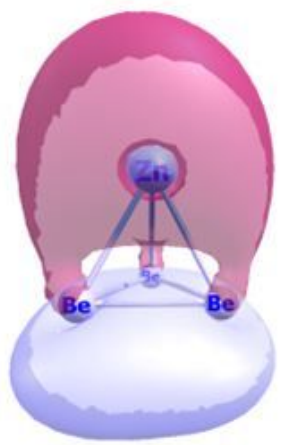

Homo-3

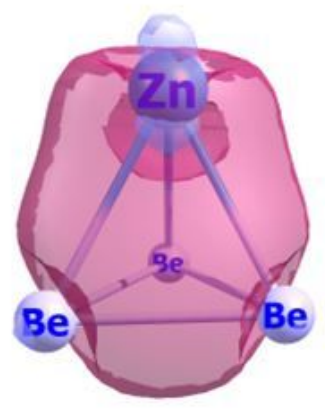

Homo-4

\section{$\mathrm{Be}_{3}-\mathrm{Fe}$}

\section{$\mathrm{Be}_{3}-\mathbf{Z n}$}

Figure 2

Frontier Kohn-Sham orbitals of Be3-Fe and Be3-Zn system.
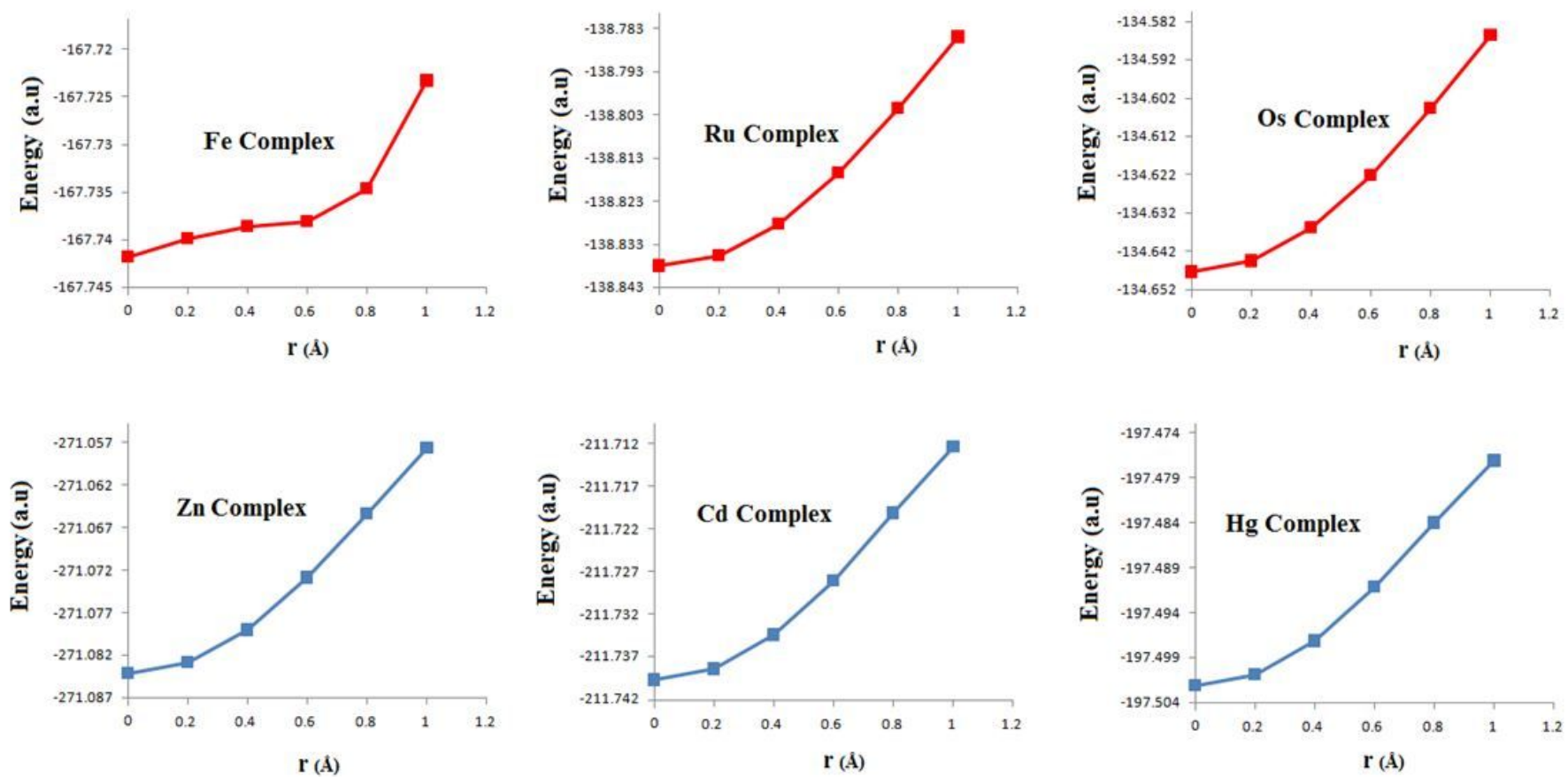

\section{Figure 3}

Plot of energy against the displacement $(r)$ of the transition metal centre in the sandwich complexes. 

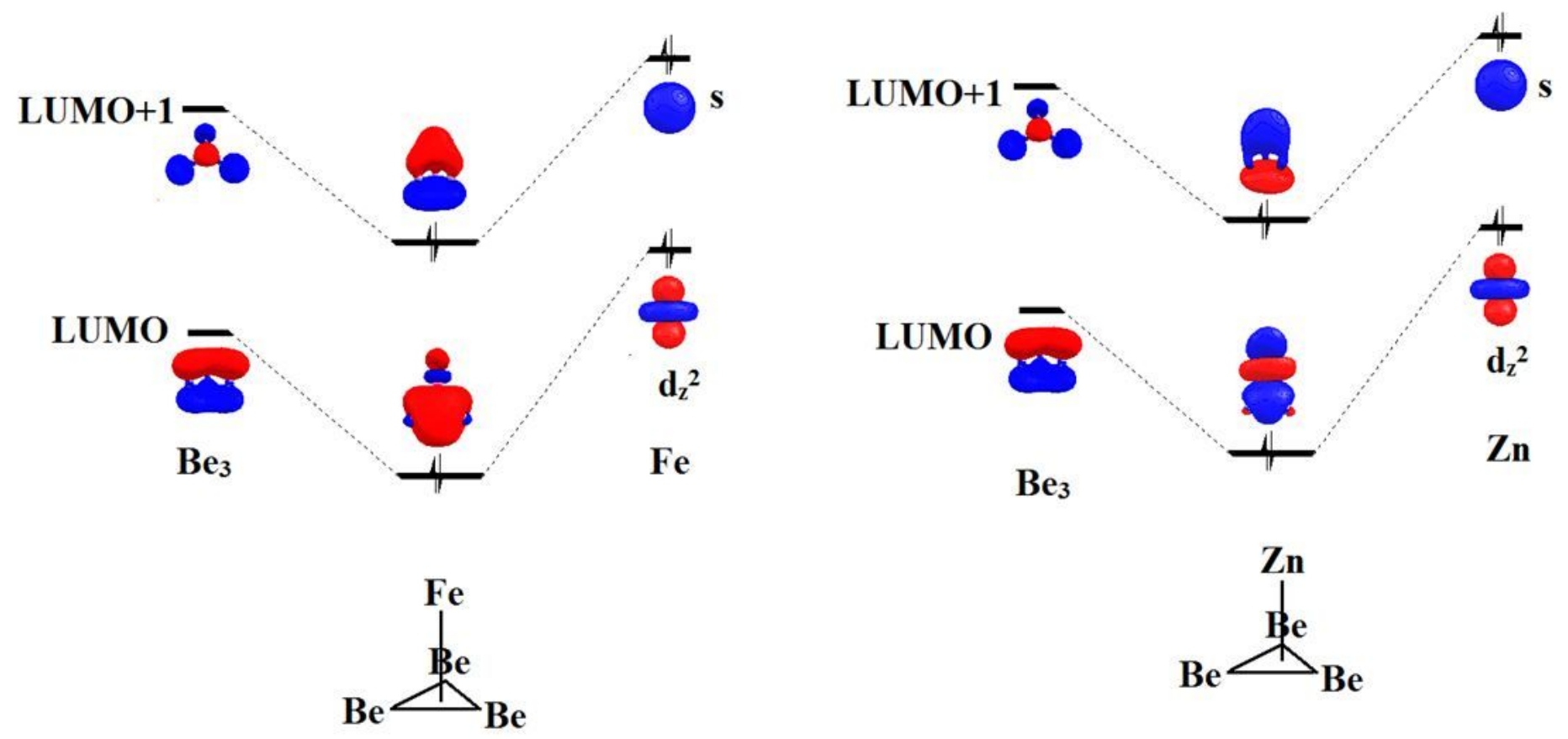

Figure 4

Orbital interaction diagram of Be3-Fe and Be3-Zn complexes.

\section{Supplementary Files}

This is a list of supplementary files associated with this preprint. Click to download.

- scheme1.jpg

- scheme2.jpg

- scheme3.jpg

- SIstructural.doc 